\title{
Effect of Trehalose and Ceftriaxone on the Stability of Aggregating-Prone Tau Peptide Containing PHF6* Sequence: An SRCD Study
}

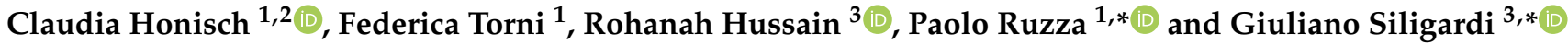 \\ 1 Institute of Biomolecular Chemistry of CNR, Padua Unit, Via Marzolo 1, 35131 Padova, Italy; \\ c.honisch@icb.cnr.it (C.H.); tornifederica@gmail.com (F.T.) \\ 2 Department of Chemical Sciences, University of Padua, Via Marzolo 1, 35131 Padova, Italy \\ 3 Diamond Light Source Ltd., Harwell Science and Innovation Campus, Didcot, Oxfordshire OX11 0DE, UK; \\ rohanah.hussain@diamond.ac.uk \\ * Correspondence: paolo.ruzza@cnr.it (P.R.); giuliano.siligardi@diamond.ac.uk (G.S.)
}

check for updates

Citation: Honisch, C.; Torni, F.; Hussain, R.; Ruzza, P.; Siligardi, G. Effect of Trehalose and Ceftriaxone on the Stability of Aggregating-Prone Tau Peptide Containing PHF6* Sequence: An SRCD Study. Int. J. Mol. Sci. 2022, 23, 2932. https:// doi.org/10.3390/ijms23062932

Academic Editor: Giuseppina Amadoro

Received: 28 January 2022

Accepted: 4 March 2022

Published: 8 March 2022

Publisher's Note: MDPI stays neutral with regard to jurisdictional claims in published maps and institutional affiliations.

Copyright: (C) 2022 by the authors. Licensee MDPI, Basel, Switzerland. This article is an open access article distributed under the terms and conditions of the Creative Commons Attribution (CC BY) license (https:// creativecommons.org/licenses/by/ $4.0 /)$.

\begin{abstract}
The tau protein, a soluble protein associated with microtubules, which is involved in the assembly and stabilization of cytoskeletal elements, was found to form neurofibrillary tangles in different neurodegenerative diseases. Insoluble tau aggregates were observed to be organized in paired helical filaments (PHFs) and straight filaments (SFs). Recently, two small sequences (306-311 and 275-280) in the microtubule-binding region (MTBR), named PHF6 and PHF6*, respectively, were found to be essential for tau aggregation. Since a possible therapeutic approach consists of impairing amyloid formation either by stabilizing the native proteins or reducing the level of amyloid precursors, here we use synchrotron radiation circular dichroism (SRCD) at Diamond B23 beamline to evaluate the inhibitory effects of two small molecules, trehalose and ceftriaxone, against the aggregation of a small peptide containing the $\mathrm{PHF}^{*}$ sequence. Our results indicate that both these molecules, ceftriaxone and trehalose, increased the stability of the peptide toward aggregation, in particular that induced by heparin. With trehalose being present in many fruits, vegetables, algae and processed foods, these results support the need to investigate whether a diet richer in trehalose might exert a protective effect toward pathologies linked to protein misfolding.
\end{abstract}

Keywords: tau protein; intrinsically disordered proteins; tauopathies; protein aggregation; trehalose; ceftriaxone; conformational stability; synchrotron radiation circular dichroism; transmission electron microscopy

\section{Introduction}

Intrinsically disordered proteins (IDPs) are a widespread class of proteins with the ability to quickly change their conformations upon participating in biological processes [1] IDP structures are highly controlled in the cell, and aberrant regulation is often associated with protein aggregation and human diseases [2].

The tau protein, a soluble protein associated with microtubules whose function is to assist the assembly and stabilization of microtubules and other cytoskeletal elements, represents an archetypical IDP found in the nervous system [3].

Neurofibrillary tangles of tau protein occur in neurons and glial cells of patients affected by different neurodegenerative diseases known as tauopathies, including, but not limited to, Alzheimer's disease, progressive supranuclear palsy, corticobasal syndrome, some frontotemporal dementias and chronic traumatic encephalopathy [4]. A strict correlation has been found between the extent and anatomical localization of tau aggregates and the progression of Alzheimer's disease [5]. At the ultrastructural level, tau aggregates are assembled in insoluble paired helical filaments (PHFs) and straight filaments (SFs) [6] 
These aggregates typically show a cross- $\beta$ pattern that is common to many aggregated proteins $[7,8]$ showing an ordered $\beta$-sheet amyloid core flanked by an unstructured coat.

Six isoforms of tau protein have been isolated in adult human brain containing either three or four pseudo-repeat units ( $3 \mathrm{R}$ or $4 \mathrm{R}$, respectively) separated by short inter-repeat regions (Figure 1) [9], both forming the microtubule-binding region (MTBR). Recently, two small sequences in the MTBR region, corresponding to the sequences 306-311 and 275-280, named PHF6 and PHF6*, respectively, were found to be essential for tau aggregation [10] (Figure 1B). The importance of the last sequence to tau aggregation has been confirmed, as its deletion slowed down the formation of aggregates [11], whilst its presence in $4 \mathrm{R}$ proteins, but not in $3 \mathrm{R}$ proteins, increased the propensity to aggregate in vitro [12]. Moreover, several tau mutations found in frontotemporal dementia are located within the PHF6* sequence [13].

Several research groups have found that short peptides derived from tau protein containing the $\mathrm{PHF}^{*}$ region $[14,15]$ form oligomeric structures rich in $\beta$-structure rather than full-fledged pairs of helical filaments. These observations indicate that the PHF6* sequence appears to play a key role in nucleating the aggregation, while other tau segments generate the PHF morphology.

A)

B)

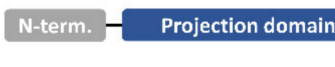

C)

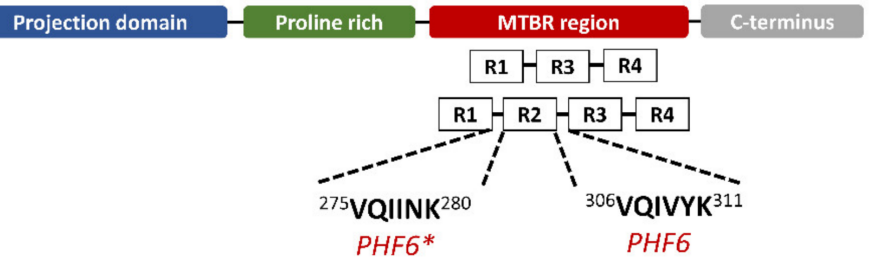

Ac-Gly-Lys-Val-GIn-Ile-Ile-Asn-Lys-Lys-Leu-Asp-Leu- $\mathrm{NH}_{2}$
$3 R$

$4 R$

tau peptide

Figure 1. Schematic structure of Tau isoforms. (A) Tau protein can be divided in three domains: the N-terminal projection domain containing two alternatively spliced exons; a proline-rich region; the microtubule-binding region (MTBR). (B) The MTBR region may contain three $(3 R)$ or four $(4 R)$ pseudo-repeat units (R1 to R4) separated by short inter-repeat regions where the PHF6 and PHF6* segments are located. (C) Sequence of the synthesized peptide. (Figure redrawn from Ref. [15]).

The aggregation of tau protein and its fragments in vitro can be induced by several agents such as arachidonic acid, RNA, and heparin. Although the question of whether heparin-induced tau aggregation is pathologically relevant is far from been resolved, it is important to note that heparin is closely related to heparansulfate that has been found in neurofibrillary tangles in Alzheimer's disease lesions [16]. Moreover, when associated with proteoglycans, heparansulfate mediates the cellular internalization and propagation of tau aggregates via a prion-like mechanism [17].

One approach in the therapy of Alzheimer's disease and other neurodegenerative pathologies characterized by the presence of protein aggregates is to block or impair amyloid formation either by stabilizing the native proteins, reducing the level of amyloid precursors or increasing the clearance of insoluble aggregates. In this context, several natural and synthetic compounds have been investigated as possible candidates [18-20]. Recently, we demonstrated that trehalose and ceftriaxone (Figure S1) may act as inhibitors of protein aggregation [21-24]. Ceftriaxone was able to successfully eliminate the cellular toxic effects of misfolded glial fibrillary acid protein (GFAP) in a cellular model of Alexander's disease [25] as well as to protect dopaminergic neurons ameliorating motor deficits in a rat model of Parkinson's disease [26]. On the other hand, trehalose, a nonreducing glucose disaccharide acting as an osmolyte that protects cells, prevented protein denaturation $[27,28]$ interfering with protein misfolding and subsequent aggregation [29].

Circular dichroism spectroscopy is the ideal tool to evaluate the capability of small molecules to interfere with protein aggregation [30,31], directly monitoring the protein/ peptide structural changes as they undergo aggregation. 
Here, we used synchrotron radiation circular dichroism (SRCD) at Diamond B23 beamline to evaluate the inhibitory effects of trehalose and ceftriaxone against the aggregation of a small peptide containing the $\mathrm{PHF}^{*}$ sequence (Figure $1 \mathrm{C}$ ). The results indicate that in the presence of heparin, the peptide adopted a $\beta$-sheet structure forming amyloid fibrils and that this conformational transition was hampered by the addition of trehalose, whilst ceftriaxone strongly modified the fibrils' morphologies, affecting the in vitro aggregation process.

\section{Results and Discussion}

The peptide corresponding to the wild-type sequence 273-284 (Ac-GKVQIINKKLDL$\mathrm{NH}_{2}$ ) of the tau protein and including the PHF6* (VQIINK) region (Figure 1C) was synthesized using solid-phase peptide synthesis. Earlier work on this peptide showed that it aggregates in vitro in a qualitatively similar manner to the full-length tau protein and is consistent with the aggregating properties of longer IDPs $[15,16]$.

\subsection{Circular Dichroism Spectroscopy}

In buffer solution, at neutral $\mathrm{pH}$ value, the $\mathrm{CD}$ spectrum of tau peptide shows the typical features of unordered conformation characterized by the presence of a negative band at about $197 \mathrm{~nm}$ (Figure 2). The incubation of peptide at $25^{\circ} \mathrm{C}$ up to $7 \mathrm{~h}$ did not induce any CD change reflecting the lack of aggregates.
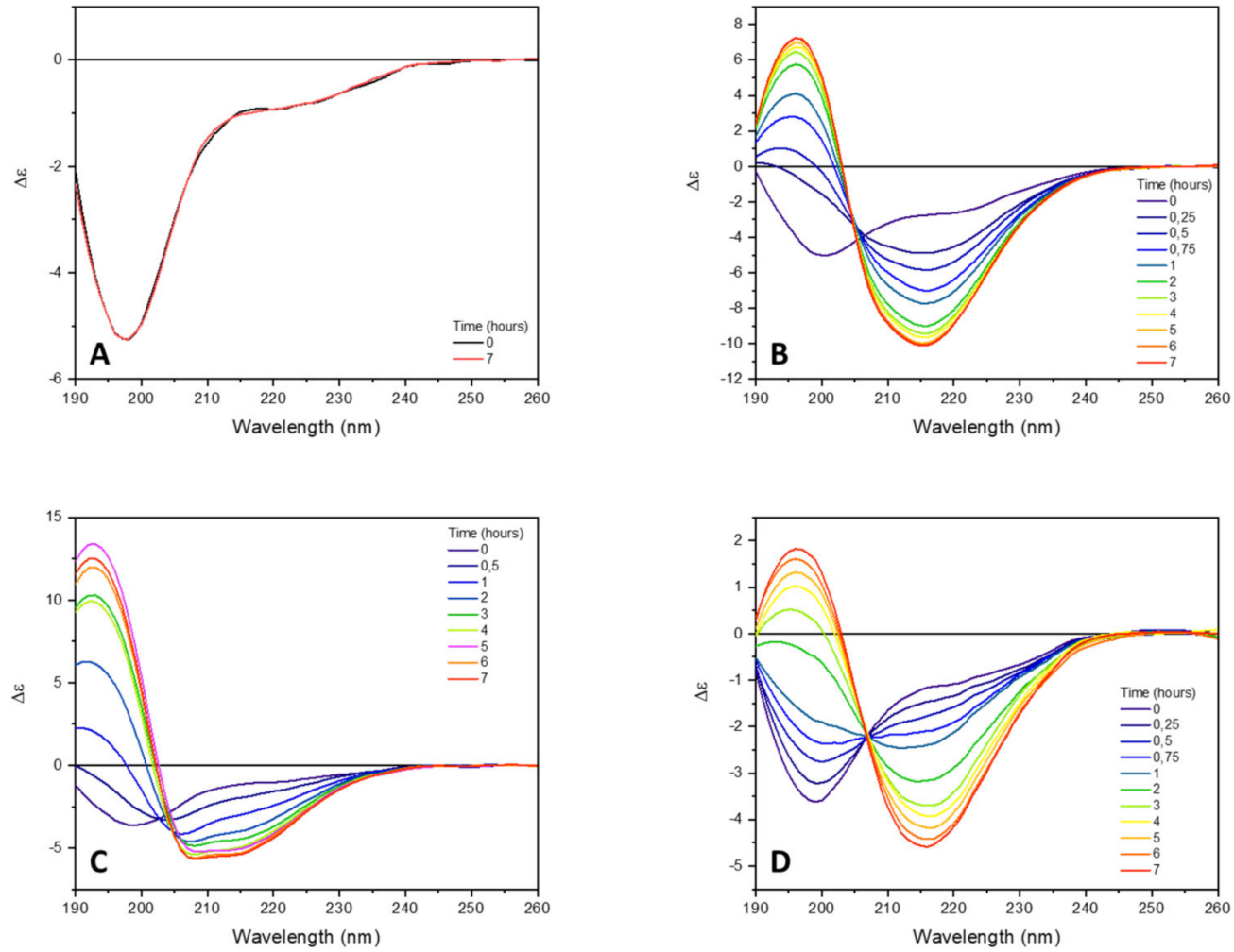

Figure 2. Far-UV SRCD spectra of tau peptide $(70.9 \mu \mathrm{M})$ in $10 \mathrm{mM}$ TRIS-HCl buffer, pH 7.4. (A) Alone; (B) in presence of 0.25 equivalents of low-molecular-weight heparin; (C) in presence of 0.25 equivalents heparin and 6 equivalents of trehalose; (D) in presence of 0.25 equivalents of heparin and 6 equivalents of ceftriaxone. CD spectra were recorded at different times of incubation at $25^{\circ} \mathrm{C}$ (indicated).

To induce and accelerate the tau peptide conformational transition from an unordered to $\beta$-sheet structure characteristic of peptide aggregation, low-molecular-weight heparin ( 0.25 equivalents) was added to the peptide solution. As shown in Figure $2 \mathrm{~B}$, the addition of heparin was accompanied by a progressive change in the CD spectrum of the tau peptide, coinciding with a conformational transition of the peptide from an unordered to a $\beta$-sheet 
conformation. Indeed, after $7 \mathrm{~h}$ of incubation at $25^{\circ} \mathrm{C}$, the $\mathrm{CD}$ spectrum of tau peptide revealed the presence of a negative band at about $216 \mathrm{~nm}$ and a positive $C D$ band at about $197 \mathrm{~nm}$, characteristic of a $\beta$-sheet conformation.

Little or no change in the CD spectrum was observed after $7 \mathrm{~h}$ (data not shown), indicating that the conformational transition was completed in that time frame. The secondary structure estimation (SSE) from the CD data using the BeStSel algorithm $[32,33]$ revealed an increase in the $\beta$-sheet content up to $41.7 \%$ (Table 1 and Figure 3), mostly attributable to the formation of a parallel $\beta$-sheet structure, accompanied by a decrease in the content of antiparallel $\beta$-sheet and unordered secondary structures. An isodichroic point at about $204 \mathrm{~nm}$ was consistent with a single-phase transition from the initially unordered structure of tau peptide to the final $\beta$-sheet conformation after the addition of heparin.

Table 1. Percentage of secondary structure content of tau peptide after $7 \mathrm{~h}$ of incubation at $25^{\circ} \mathrm{C}$ in presence of different molecules, along with the normalized root mean square error deviation (NRMSD) associated with the calculation.

\begin{tabular}{cccccccc}
\hline & \multicolumn{7}{c}{ \% Secondary Structure Estimation } \\
\hline & $\boldsymbol{\alpha}$ & $\boldsymbol{\beta}_{\text {anti }}$ & $\boldsymbol{\beta}_{\text {parallel }}$ & $\boldsymbol{\beta}_{\text {tot }}$ & Turn & Unordered & NRMSD \\
\hline tau peptide & 15.1 & 22.5 & 0 & 22.5 & 14.3 & 48.1 & 0.024 \\
+ heparin & 36.5 & 7.2 & 34.6 & 41.8 & 0 & 21.7 & 0.048 \\
+ hep and treh & 48.6 & 20.4 & 0 & 20.4 & 5 & 26 & 0.017 \\
+ hep and cef & 14.2 & 15.5 & 10.8 & 26.3 & 12.4 & 47.1 & 0.037 \\
\hline
\end{tabular}
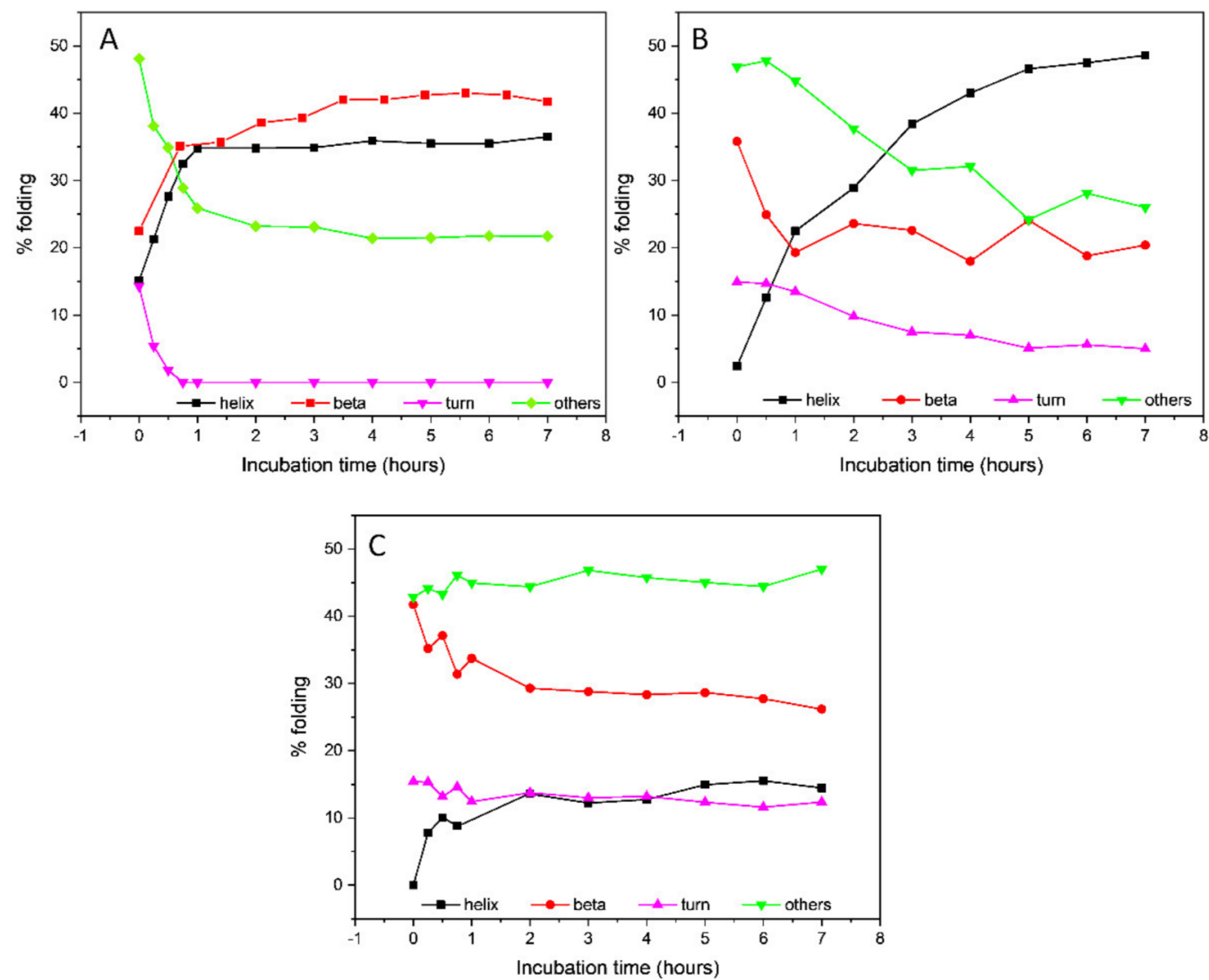

Figure 3. Secondary structure estimation of Tau peptide in presence of either (A) 0.25 eq. lowmolecular-weight heparin, (B) 0.25 eq. heparin and 6 eq. trehalose or (C) 0.25 eq. heparin and 6 eq. ceftriaxone throughout $7 \mathrm{~h}$ incubation time. 
To better understand the conformational transition of the tau peptide in the presence of heparin, the set of acquired CD spectra was analyzed using singular value decomposition (SVD) analysis to extract the key spectral components and their kinetics. SVD decomposed the data set into three distinct sections: a basis set that represented the independent spectral features; kinetic traces for each of these features, describing their contribute to each time; and a weight value (W) that ranked the importance of each basis spectrum, providing an unbiased rationale for the reduction in the basis set dimension.

Figure S2 in the Supplementary Materials depicts six basis spectra generated by the SVD analysis implement in the CDApps software [34], their associated kinetics, and weight values. As the spectral features are merely a mathematical representation of the data, they can have both positive and negative amplitudes. The contribution of each basis spectrum fell rapidly, and only the first two spectra were utilized for analysis, being consistent with a single-phase transition. Indeed, the sum of the squares of these two singular weight values represented $99.95 \%$ of the total sum.

To extract the spectra of these two species in the data set, a kinetic model based on the conversion of $A$ into $B(A \rightarrow B)$ was used along with SVD. The determined spectra of $A$ and $\mathrm{B}$ species as well as the kinetics of the structural transformation are reported in Figure 4 and correspond to the CD spectra of the peptide at time zero (specie A) and after $7 \mathrm{~h}$ of incubation (specie B).
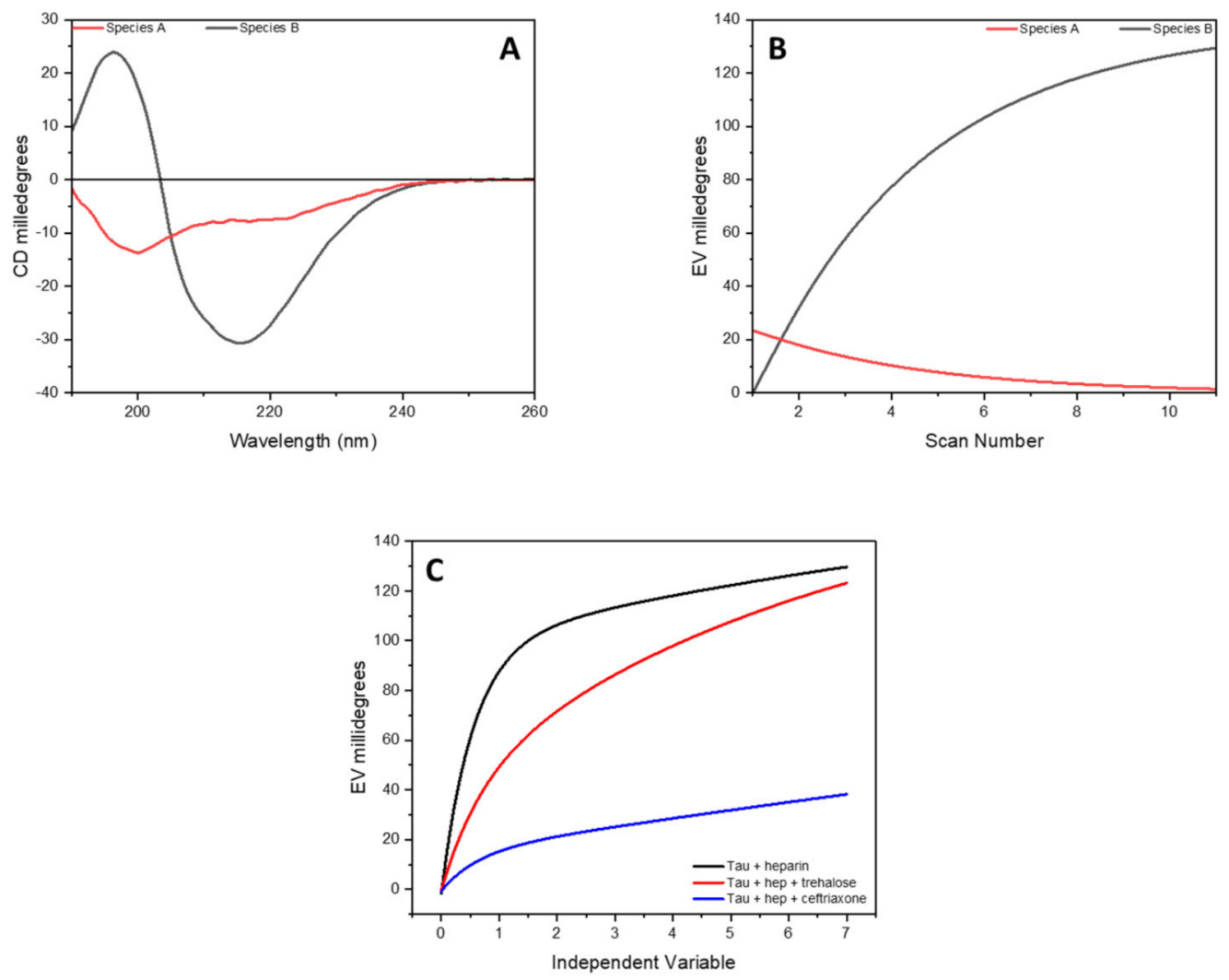

Figure 4. SVD analysis of complete data set of CD spectra of tau peptide for the conformational conversion of peptide induced by low-molecular-weight heparin. (A) CD spectra of the initial (specie $\mathrm{A}$, in red) and final (specie B, in black) conformation of tau peptide in presence of 0.25 equivalents of heparin; (B) the time-dependent amplitude of the two species of tau peptide; (C) influence of trehalose or ceftriaxone on the conformational conversion of tau peptide induced by heparin.

To assess whether trehalose or ceftriaxone could interfere with or modulate the conformational conversion of tau peptide from unordered to $\beta$-sheet induced by heparin, $C D$ 
experiments were carried out, monitoring the $\mathrm{CD}$ as a function of time upon the addition of either trehalose or ceftriaxone to the mixture of tau peptide with heparin.

The addition of six equivalents of trehalose to the peptide-heparin solution strongly modified the overall CD profile shape (Figure $2 \mathrm{C}$ ) compared to that observed in presence of the heparin alone (Figure 2B). In particular, the CD spectrum recorded after $7 \mathrm{~h}$ of incubation at $25^{\circ} \mathrm{C}$ showed two negative bands at 208 and $217 \mathrm{~nm}$, while the positive band at $197 \mathrm{~nm}$ shifted to lower wavelengths (Figure 2C), resembling that of an $\alpha$-helix structure. Additionally, in the presence of trehalose, any further change in the CD spectrum was observed after $7 \mathrm{~h}$ of incubation at $25^{\circ} \mathrm{C}$. The secondary structure estimation (SSE) analysis confirmed that in the presence of trehalose, the conformational conversion of tau peptide induced by heparin was strongly modified. Indeed, as reported in Table 1 and in Figure 3, at the end of the incubation time tau peptide adopted an $\alpha$-helix secondary structure (48.6\%), while the $\beta$-sheet content $(20.4 \%)$, exclusively due to antiparallel structure, was similar to that estimated for the native peptide in the absence of heparin.

To evaluate the influence of trehalose on the conformation of tau peptide, six equivalents of trehalose were added to a peptide solution in the absence of heparin and incubated for $7 \mathrm{~h}$ at $25^{\circ} \mathrm{C}$. As shown in Figure S3 in the Supplementary Materials, no CD changes were observed as a function of time, confirming that trehalose did not affect the tau peptide conformation.

Even in the presence of heparin and trehalose, an isodichroic point was observed at about $205 \mathrm{~nm}$, suggesting the presence of a single-phase transition from the initially unordered structure and the ordered conformation adopted by tau peptide after $7 \mathrm{~h}$ of incubation. The SVD analysis (Figure S4 in Supplementary Materials) of this set of CD spectra showed how even in the presence of heparin and trehalose, the contribution of each basis spectrum decreased rapidly, and only the first two spectra were used for the analysis (the sum of the squares of these values corresponds to $99,98 \%$ of the entire sum), confirming the presence of an equilibrium between two species. It was therefore possible to use the previously described kinetic model $(A \rightarrow B)$ in order to determine the $C D$ spectra of the species present at time 0 and at the end of the conformational transition of tau peptide, as well as the kinetics of the conversion (Figure S5 in Supplementary Materials).

Similarly, the effects of ceftriaxone on conformational conversion induced by heparin were evaluated. The set of $C D$ spectra recorded in the presence of both heparin and ceftriaxone was reported in Figure 2D. The CD spectrum recorded at the end of the conformational transition closely resembled that acquired in the presence of heparin alone, with a strong positive band at $196 \mathrm{~nm}$, a broad negative band centered at about $212 \mathrm{~nm}$ and an isodichroic point at $204 \mathrm{~nm}$. Even in the presence of ceftriaxone, any significant change in the CD spectrum of tau peptide in the presence of heparin were observed after $7 \mathrm{~h}$ (data not shown), as well as any effect of ceftriaxone upon the addition to the peptide alone (Figure S6 in Supplementary Materials). The SSE at the end of the incubation time revealed a decrease in the content of ordered structures ( $\alpha$-helix and $\beta$-sheet) and an increment in the contribution of unordered structure compared to that of the sample incubated in the presence of heparin alone (Table 1 and Figure 3).

The SVD analysis (Figure S7 in Supplementary Materials) of this set of spectra indicated that in the presence of ceftriaxone, the system can also be ascribed as a single-phase transition with a kinetic model based on two species (Figure S8 in Supplementary Materials).

A comparison of the time-dependent amplitude of the appearance of specie B determined via SVD analysis is reported in Figure 4, where it can be seen how, in the presence of trehalose or ceftriaxone, a decrease in the conversion rate of the tau peptide was detected, suggesting a protective role of these two molecules toward the activity of heparin.

The thermal stability of the product of the conformational conversion of tau peptide induced by heparin with and without trehalose was evaluated. The change in the CD spectra as a function of temperature were visually evident from both melt series spectra (Figure 5A-C) and melt curves obtained by plotting the measured molar circular dichroism values of the negative bands versus temperature (Figure 5D). 

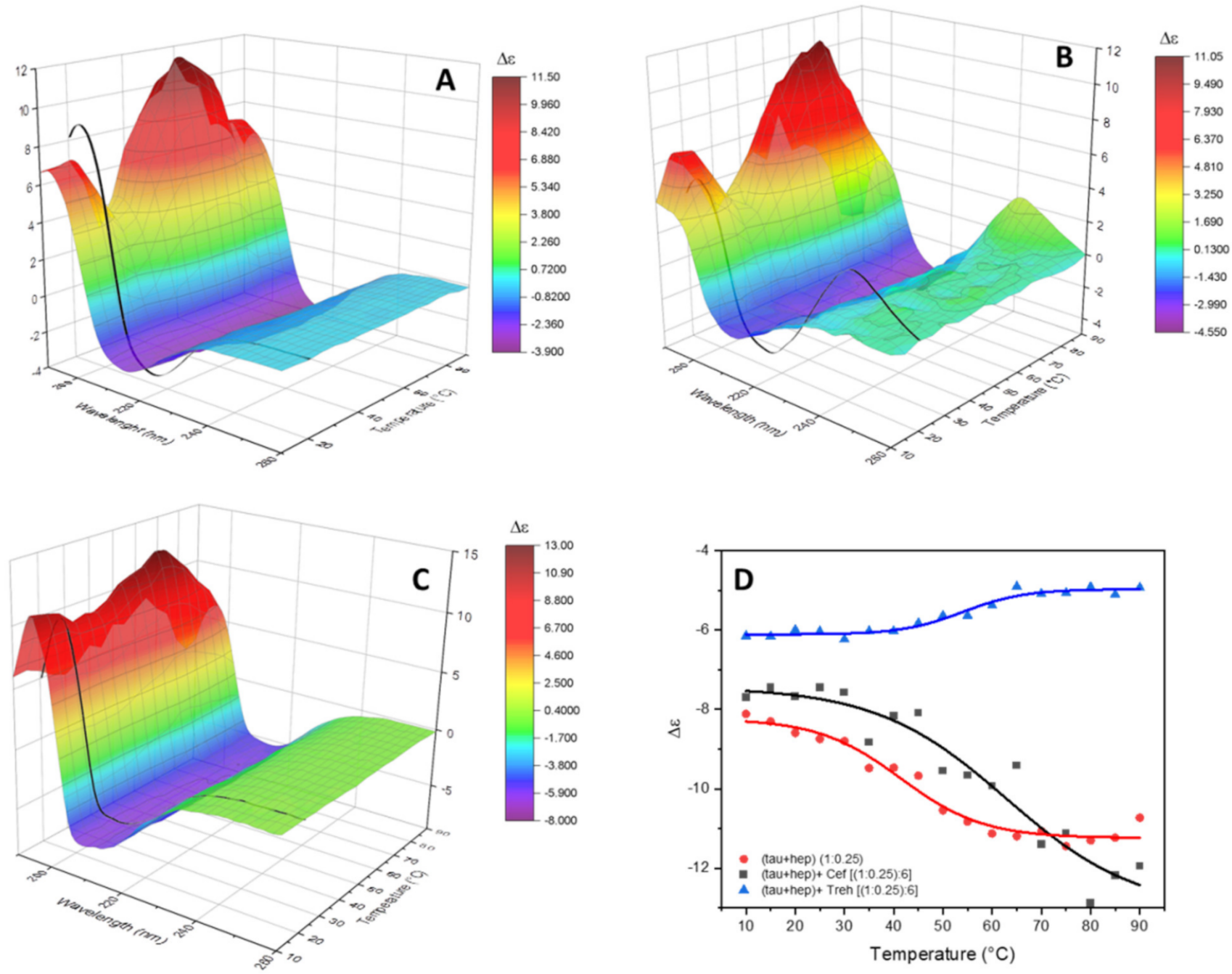

Figure 5. Temperature melting experiments. SRCD spectra in the $10-90{ }^{\circ} \mathrm{C}$ range recorded at $5{ }^{\circ} \mathrm{C}$ steps, represented as 3D surface map, of tau peptide in presence of low-molecular-weight heparin (A), of heparin and ceftriaxone (B) or of heparin and trehalose (C). In black, the SRCD spectrum of the analyzed solution recorded cooled back at $20^{\circ} \mathrm{C}$ after the temperature ramping. (D) Melt curves built plotting the ellipticity value at $215 \mathrm{~nm}$ of tau peptide in presence of heparin alone (red line) or heparin and ceftriaxone (black line) or at $208 \mathrm{~nm}$ for heparin and trehalose (blue line).

In the presence of heparin alone (Figure 5A), the set of $\mathrm{CD}$ spectra were characterized by an increased intensity of the negative band at $215 \mathrm{~nm}$ upon increased temperature, and the positive band at $197 \mathrm{~nm}$ showed a biphasic trend, initially decreasing up to $30{ }^{\circ} \mathrm{C}$, then increasing up to $60{ }^{\circ} \mathrm{C}$ and then decreasing again. The secondary structure estimation analysis (Figure S9 in Supplementary Materials) shows the presence of more conformational transitions of tau peptide upon the increased temperature. The melt curve obtained, plotting the intensity of the negative band at $215 \mathrm{~nm}$ versus the temperature, enabled the determination of $\mathrm{T} m$ of $40^{\circ} \mathrm{C}$ for the tau peptide with heparin.

In the presence of ceftriaxone, very similar melt series spectra were observed (Figure 5B), while the secondary structure estimation analysis showed a constant increase in the contribution of the unordered structure upon increasing the temperature (Figure S9B in Supplementary Materials). The T $m$ of tau peptide with both heparin and ceftriaxone calculated using the intensity of the negative band at $215 \mathrm{~nm}$ increased to $62{ }^{\circ} \mathrm{C}$. This increment in the $\mathrm{T} m$ value confirmed the presence of an interaction between tau peptide and ceftriaxone that stabilized the secondary structure of peptide. 
The set of CD spectra recorded as a function of temperature in presence of both heparin and trehalose (Figure 5C) were characterized by a decrease in the intensity of the negative band at $208 \mathrm{~nm}$ upon increasing the temperature, while the estimation of secondary structure content (Figure S9C in Supplementary Materials) showed a slight decrease in the amount of $\alpha$-helix conformation. An increased T $m$ value of tau peptide with heparin and trehalose of $58^{\circ} \mathrm{C}$ was indicative of binding interactions between trehalose and tau peptide, hence stabilizing the peptide conformation against aggregation.

\subsection{Transmission Electron Microscopy}

The morphology of tau peptide was evaluated using negative staining transmission electron microscopy (TEM). As shown in Figure 6A, incubation with shaking of the tau peptide $\mathrm{CD}$ solution alone induces poor aggregation, and few amorphous aggregates were observed after one week of incubation (data not shown) according to the previous work of Mandelkow et al. [35].
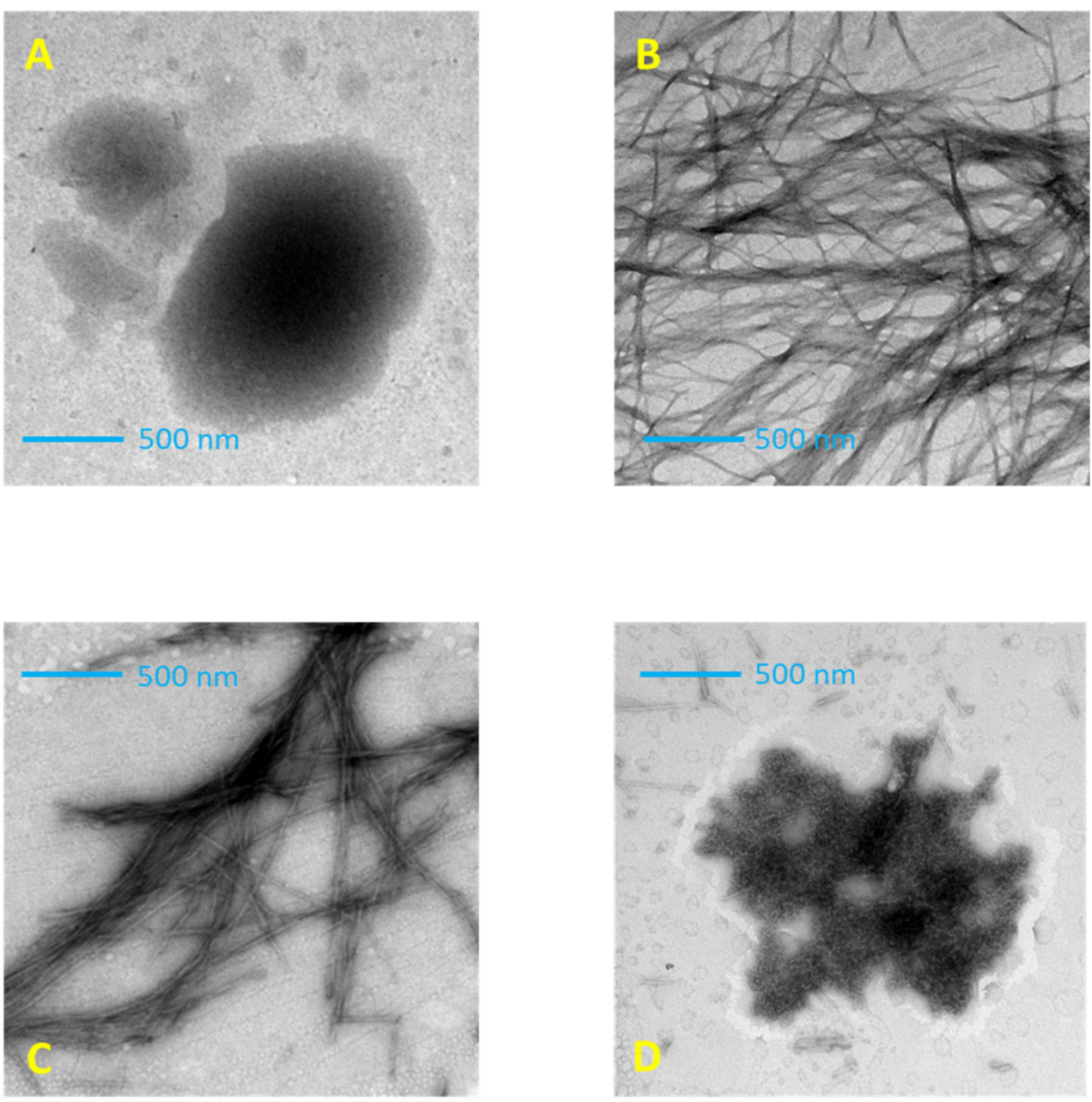

Figure 6. Transmission electron microscopy (TEM) imaging of tau peptide $(70.9 \mu \mathrm{M})$ in $10 \mathrm{mM}$ TRIS-HCl buffer, pH 7.4 after $7 \mathrm{~h}$ incubation at $25{ }^{\circ} \mathrm{C}$. (A) Tau peptide alone; (B) in presence of 0.25 molar equivalents of low-molecular-weight heparin; (C) in presence of 0.25 molar equivalents of heparin and 6 molar equivalents of ceftriaxone; (D) in presence of 0.25 molar equivalents of heparin and 6 molar equivalents of trehalose.

The TEM analysis of peptide-heparin CD solution incubated with shaking at $25^{\circ} \mathrm{C}$ revealed a mesh of interwoven filaments with a typical amyloid morphology consisting of networks of long, unbranched fibers greater than $500 \mathrm{~nm}$ (Figure 6B), confirming the ability 
of heparin to induce peptide aggregation and fibrillation, acting as a structured template for peptide self-assembly [36].

The TEM analysis of the peptide-heparin solution with added ceftriaxone still showed the presence of fibrillar structures, but with different morphologies compared to those previously described. Indeed, in the presence of ceftriaxone, the filament density was reduced, and the filaments were sparsely distributed. These remaining filaments were considerably shorter than the untreated fibrils and had greater thicknesses (Figure 6C). The TEM images concur with the $\mathrm{CD}$ indicating that ceftriaxone induces a different conformation of the tau peptide, resulting in modification of the fibril formation.

On the other hand, the presence of trehalose strongly modified the morphology of tau peptide aggregates. The addition of trehalose induced the disappearance of fibrillar structures with the appearance of amorphous aggregates (Figure 6D), confirming the $C D$ results that indicate the absence of $\beta$-sheet structures. However, these aggregates differ in shape and size from those observed for the tau peptide alone (Figure 6A) and are consistent with the different secondary structure determined by $C D$.

\section{Materials and Methods}

\subsection{Peptide Synthesis}

Tau peptide was synthesized via solid phase peptide synthesis (SPPS) using Fmoc/DIC /Oxyma chemistry [37], which was carried out automatically on a Biotage ${ }^{\circledR}$ Syro Wave ${ }^{\mathrm{TM}}$ Automated Microwave and Parallel Peptide Synthesizer (Biotage AB, Uppsala, Sweden) controlled by "SyroXP peptide" software. The N-terminal was acetylated via treatment with acetic anhydride, and successively the peptide was detached from the resin via treatment with TFA in the presence of triisopropylsylane and water as scavengers. This procedure achieved the simultaneous removal of sidechain-protecting groups. The crude peptide was precipitated via the addition of diethyl ether, and then the crude peptide was purified via RP-HPLC using a Dionex Vydac C18, $300 \AA, 10 \mu, 22 \times 250 \mathrm{~mm}$ column (Thermo Fisher Scientific, Sunnyvale, CA, USA) mounted on a preparative Shimadzu HPLC system (Kyoto, Japan) equipped with LC-8A pumps, SLC-8A controller, an SPD-6A spectrophotometric detector and an ERC-3562 ERMA degasser (Erma, Tokyo, Japan).

The identity and purity of the synthesized peptide was determined via LC-ESI-MS analysis conducted using an Agilent 1260 Infinity II system equipped with a 6130 Quadrupole LC-MS analyzer.

\subsection{Synchrotron Radiation Circular Dichroism}

The secondary structure of tau peptide $(70.9 \mu \mathrm{M})$ in $10 \mathrm{mM}$ TRIS-HCl buffer, $\mathrm{pH} 7.4$, alone or in the presence of low-molecular-weight heparin ( 0.25 equivalents), in the presence or absence of 6 equivalents of trehalose or ceftriaxone, were monitored for up to $7 \mathrm{~h}$ by acquiring far-UV SRCD spectra in the 190-260 $\mathrm{nm}$ range at Module B end station of Diamond Light Source Ltd. (Harwell Science and Innovation Campus, Didcot, UK) Beamline B23, using a $0.1 \mathrm{~cm}$ pathlength Suprasil quartz cuvette (Hellma Analytics, Müllheim, Germany), with $0.2 \mathrm{~nm}$ data pitch, $1 \mathrm{~nm}$ bandwidth, $1 \mathrm{~s}$ digital integration time and scan speed of $39 \mathrm{~nm} / \mathrm{min}$.

SRCD melting experiments on the different tau solutions in the absence or presence of 6 molar equivalents of alternatively trehalose or ceftriaxone after $7 \mathrm{~h}$ of incubation at $25^{\circ} \mathrm{C}$ were performed in the $10-90^{\circ} \mathrm{C}$ temperature range with $5{ }^{\circ} \mathrm{C}$ temperature increases and 3 min of equilibration time. After the measurement at $90^{\circ} \mathrm{C}$, the solutions were allowed to cool back to room temperature, and an additional SRCD spectrum was recorded after $8 \mathrm{~min}$ of equilibration time at $20^{\circ} \mathrm{C}$. Measurements were collected in the $190-260 \mathrm{~nm}$ range at Module B station of Diamond Light Source Beamline B23, using a $0.1 \mathrm{~cm}$ pathlength quartz cuvette (Hellma Analytics) with $0.2 \mathrm{~nm}$ data pitch, $1 \mathrm{~nm}$ bandwidth, $1 \mathrm{~s}$ digital integration time and scan speed of $39 \mathrm{~nm} / \mathrm{min}$.

Spectra were plotted using OriginPro2018 software (OriginLab Corporation, Northampton, MA, USA) and analyzed using the CDApps software [34] for Singular Value Decom- 
position analysis (SVD) and the web-available software BeStSel [32] to perform secondary structure estimation.

\subsection{Transmission Electron Microscopy (TEM) Imaging}

TEM images were taken on an FEI Tecnai G2 transmission electron microscope (Thermo Fisher Scientific, Waltham, MA, USA), operating at an excitation voltage of $100 \mathrm{kV}$. Specimen searching was carried out in diffraction mode at a low dose rate, which then quickly switched to image mode for immediate image acquisition. Sample preparation included staining with $1 \%$ uranyl acetate. Images were acquired using a Veleta digital camera (Olympus Soft Imaging System, Münster, Germany).

\section{Conclusions}

In this study, circular dichroism spectroscopy was utilized to monitor the conformational conversion of a short peptide, corresponding to the sequence 273-284 of tau protein and containing the $\mathrm{PHF}^{*}$ region involved in the protein aggregation, induced by lowmolecular-weight heparin. Furthermore, the influence of small molecules, ceftriaxone and trehalose, of which we had previously demonstrated the antiaggregating properties toward $\alpha$-synuclein and GFAP proteins, on the conformational conversion process was evaluated.

We reported experimental evidence that both these molecules, ceftriaxone and trehalose, interacted with tau peptide in the presence of heparin, increasing the Tm, which is an indication of ligand binding interaction and the increased stability of the peptide toward aggregation, and more importantly, interfering with the peptide aggregation induced by heparin. As confirmed by TEM analysis, while the addition of ceftriaxone slightly modified the morphology of the peptidic aggregates, reducing the number of fibrils and increasing their diameter, the presence of trehalose removed the formation of fibrils by promoting $\alpha$-helix conformation in tau peptide. Indeed, the TEM analysis revealed the presence of amorphous aggregates, morphologically different from those obtained with the native peptide in the absence of any additive (heparin and/or small molecules).

Overall, the data presented here confirm our previous results on the protective effects of trehalose toward protein aggregation and fibrillation, generalizing its effect on a wide range of proteins. It is important to note that trehalose is present in many fruits, vegetables, algae and processed foods. This work supports the need to investigate whether a diet richer in trehalose both from the intake of these foods or for the consumption of foods enriched with it might have an effect that protects or slows down the onset of pathologies linked to protein misfolding.

Supplementary Materials: The following supporting information can be downloaded at: https: //www.mdpi.com/article/10.3390/ijms23062932/s1.

Author Contributions: Conceptualization, P.R. and G.S.; methodology, P.R. and C.H.; software, R.H. and G.S.; formal analysis, P.R., C.H. and R.H.; investigation, C.H and F.T.; data curation, P.R. and C.H.; writing—original draft preparation, P.R. writing—review and editing, G.S. and R.H.; All authors have read and agreed to the published version of the manuscript.

Funding: This research received no external funding.

Conflicts of Interest: The authors declare no conflict of interest.

\section{References}

1. Uversky, V.N.; Kulkarni, P. Intrinsically disordered proteins: Chronology of a discovery. Biophys. Chem. 2021, 279, 106694. [CrossRef] [PubMed]

2. Monti, S.M.; De Simone, G.; Langella, E. The Amazing World of IDPs in Human Diseases. Biomolecules 2021, 11, 333. [CrossRef] [PubMed]

3. Guo, T.; Noble, W.; Hanger, D.P. Roles of tau protein in health and disease. Acta Neuropathol. 2017, 133, 665-704. [CrossRef] [PubMed]

4. Orr, M.E.; Sullivan, A.C.; Frost, B. A Brief Overview of Tauopathy: Causes, Consequences, and Therapeutic Strategies. Trends Pharmacol. Sci. 2017, 38, 637-648. [CrossRef] 
5. Mamun, A.A.; Uddin, M.S.; Mathew, B.; Ashraf, G.M. Toxic tau: Structural origins of tau aggregation in Alzheimer's disease. Neural Regen. Res. 2020, 15, 1417-1420.

6. Skrabana, R.; Sevcik, J.; Novak, M. Intrinsically disordered proteins in the neurodegenerative processes: Formation of tau protein paired helical filaments and their analysis. Cell Mol. Neurobiol. 2006, 26, 1085-1097. [CrossRef]

7. Almeida, Z.L.; Brito, R.M.M. Structure and Aggregation Mechanisms in Amyloids. Molecules 2020, 25, 1195. [CrossRef]

8. Mukrasch, M.D.; Biernat, J.; von Bergen, M.; Griesinger, C.; Mandelkow, E.; Zweckstetter, M. Sites of Tau Important for Aggregation Populate $\beta$-Structure and Bind to Microtubules and Polyanions. J. Biol. Chem. 2005, 280, 24978-24986. [CrossRef]

9. Bachmann, S.; Bell, M.; Klimek, J.; Zempel, H. Differential Effects of the Six Human TAU Isoforms: Somatic Retention of 2N-TAU and Increased Microtubule Number Induced by 4R-TAU. Front. Neurosci. 2021, 15, 547. [CrossRef]

10. Smit, F.X.; Luiken, J.A.; Bolhuis, P.G. Primary Fibril Nucleation of Aggregation Prone Tau Fragments PHF6 and PHF6*. J. Phys. Chem. B 2017, 121, 3250-3261. [CrossRef]

11. Li, W.; Lee, V.M.Y. Characterization of Two VQIXXK Motifs for Tau Fibrillization in Vitro. Biochemistry 2006, 45, 15692-15701. [CrossRef]

12. Combs, B.; Voss, K.; Gamblin, T.C. Pseudohyperphosphorylation has differential effects on polymerization and function of tau isoforms. Biochemistry 2011, 50, 9446-9456. [CrossRef]

13. Von Bergen, M.; Barghorn, S.; Li, L.; Marx, A.; Biernat, J.; Mandelkow, E.M.; Mandelkow, E. Mutations of tau protein in frontotemporal dementia promote aggregation of paired helical filaments by enhancing local beta-structure. J. Biol. Chem. 2001, 276, 48165-48174. [CrossRef]

14. Levine, Z.A.; Larini, L.; LaPointe, N.E.; Feinstein, S.C.; Shea, J.-E. Regulation and aggregation of intrinsically disordered peptides. Proc. Natl. Acad. Sci. USA 2015, 112, 2758-2763. [CrossRef]

15. Larini, L.; Gessel, M.M.; LaPointe, N.E.; Do, T.D.; Bowers, M.T.; Feinstein, S.C.; Shea, J.-E. Initiation of assembly of tau (273-284) and its $\Delta$ K280 mutant: An experimental and computational study. Phys. Chem. Chem. Phys. 2013, 15, 8916-8928. [CrossRef]

16. Lorente-Gea, L.; García, B.; Martín, C.; Ordiales, H.; García-Suárez, O.; Piña-Batista, K.M.; Merayo-Lloves, J.; Quirós, L.M.; Fernández-Vega, I. Heparan Sulfate Proteoglycans Undergo Differential Expression Alterations in Alzheimer Disease Brains. J. Neuropathol. Exp. Neurol. 2020, 79, 474-483. [CrossRef]

17. Holmes, B.B.; DeVos, S.L.; Kfoury, N.; Li, M.; Jacks, R.; Yanamandra, K.; Ouidja, M.O.; Brodsky, F.M.; Marasa, J.; Bagchi, D.P.; et al. Heparan sulfate proteoglycans mediate internalization and propagation of specific proteopathic seeds. Proc. Natl. Acad. Sci. USA 2013, 110, E3138-E3147. [CrossRef]

18. Ruzza, P. Small Molecules that Ameliorate Protein Misfolding. In Advances in Organic Synthesis; Atta-ur-Rahman, F., Ed.; Bentham Science Publishers: Sharjah, United Arab Emirates, 2017; Volume 7, pp. 3-30.

19. Marchiani, A.; Mammi, S.; Siligardi, G.; Hussain, R.; Tessari, I.; Bubacco, L.; Delogu, G.; Fabbri, D.; Dettori, M.A.; Sanna, D.; et al Small molecules interacting with $\alpha$-synuclein: Antiaggregating and cytoprotective properties. Amino Acids 2013, 45, 327-338. [CrossRef]

20. Honisch, C.; Hussain, R.; Siligardi, G.; Ruzza, P. Influence of small molecules on the photo-stability of water soluble porcine lens proteins. Chirality 2020, 32, 611-618. [CrossRef]

21. Ruzza, P.; Hussain, R.; Biondi, B.; Calderan, A.; Tessari, I.; Bubacco, L.; Siligardi, G. Effects of Trehalose on Thermodynamic Properties of Alpha-synuclein Revealed through Synchrotron Radiation Circular Dichroism. Biomolecules 2015, 5, 724-734. [CrossRef]

22. Ruzza, P.; Siligardi, G.; Hussain, R.; Marchiani, A.; Islami, M.; Bubacco, L.; Delogu, G.; Fabbri, D.; Dettori, M.A.; Sechi, M.; et al. Ceftriaxone blocks the polymerization of $\alpha$-synuclein and exerts neuroprotective effects in vitro. ACS Chem. Neurosci. 2014, 5, 30-38. [CrossRef]

23. Ruzza, P.; Vitale, R.M.; Hussain, R.; Montini, A.; Honisch, C.; Pozzebon, A.; Hughes, C.S.; Biondi, B.; Amodeo, P.; Sechi, G.; et al. Chaperone-like effect of ceftriaxone on HEWL aggregation: A spectroscopic and computational study. Biochim. Biophys. Acta Gen. Sub. 2018, 1862, 1317-1326. [CrossRef]

24. Ruzza, P.; Vitale, R.M.; Hussain, R.; Biondi, B.; Amodeo, P.; Sechi, G.; Siligardi, G. Interactions of GFAP with ceftriaxone and phenytoin: SRCD and molecular docking and dynamic simulation. Biochim. Biophys. Acta 2016, 1860, 2239-2248. [CrossRef]

25. Sechi, G.; Matta, M.; Deiana, G.A.; Balbi, P.; Bachetti, T.; Di Zanni, E.; Ceccherini, I.; Serra, A. Ceftriaxone has a therapeutic role in Alexander disease. Prog. Neuro-Psychopharmacol. Biol. Psychiatry 2010, 34, 416-417. [CrossRef]

26. Leung, T.C.H.; Lui, C.N.P.; Chen, L.W.; Yung, W.H.; Chan, Y.S.; Yung, K.K.L. Ceftriaxone Ameliorates Motor Deficits and Protects Dopaminergic Neurons in 6-Hydroxydopamine-Lesioned Rats. ACS Chem. Neurosci. 2012, 3, 22-30. [CrossRef]

27. Jain, N.K.; Roy, I. Effect of trehalose on protein structure. Protein Sci. 2009, 18, 24-36. [CrossRef]

28. Luyckx, J.; Baudouin, C. Trehalose: An intriguing disaccharide with potential for medical application in ophthalmology. Clin Ophthalmol. 2011, 5, 577-581. [PubMed]

29. Siddhanta, S.; Barman, I.; Narayana, C. Revealing the trehalose mediated inhibition of protein aggregation through lysozymesilver nanoparticle interaction. Soft Matter 2015, 11, 7241-7249. [CrossRef] [PubMed]

30. Chemes, L.B.; Alonso, L.G.; Noval, M.G.; de Prat-Gay, G. Circular dichroism techniques for the analysis of intrinsically disordered proteins and domains. Methods Mol. Biol. 2012, 895, 387-404. [PubMed]

31. Chen, S.; Yin, H.; Zhang, L.; Liu, R.; Qi, W.; He, Z.; Su, R. Oligomeric procyanidins inhibit insulin fibrillation by forming unstructured and off-pathway aggregates. RSC Adv. 2021, 11, 37290-37298. [CrossRef] 
32. Micsonai, A.; Wien, F.; Bulyáki, É.; Kun, J.; Moussong, É.; Lee, Y.-H.; Goto, Y.; Réfrégiers, M.; Kardos, J. BeStSel: A web server for accurate protein secondary structure prediction and fold recognition from the circular dichroism spectra. Nucleic Acids Res. 2018, 46, W315-W322. [CrossRef]

33. Micsonai, A.; Wien, F.; Kernya, L.; Lee, Y.H.; Goto, Y.; Réfrégiers, M.; Kardos, J. Accurate secondary structure prediction and fold recognition for circular dichroism spectroscopy. Proc. Natl. Acad. Sci. USA 2015, 112, E3095-E3103. [CrossRef]

34. Hussain, R.; Benning, K.; Myatt, D.; Javorfi, T.; Longo, E.; Rudd, T.R.; Pulford, B.; Siligardi, G. CDApps: Integrated software for experimental planning and data processing at beamline B23, Diamond Light Source. J. Synchrotron Radiat. 2015, $22,862$. [CrossRef]

35. Mandelkow, E.; von Bergen, M.; Biernat, J.; Mandelkow, E.M. Structural principles of tau and the paired helical filaments of Alzheimer's disease. Brain Pathol. 2007, 17, 83-90. [CrossRef]

36. Ahanger, I.A.; Parray, Z.A.; Nasreen, K.; Ahmad, F.; Hassan, M.I.; Islam, A.; Sharma, A. Heparin Accelerates the Protein Aggregation via the Downhill Polymerization Mechanism: Multi-Spectroscopic Studies to Delineate the Implications on Proteinopathies. ACS Omega 2021, 6, 2328-2339. [CrossRef]

37. Behrendt, R.; White, P.; Offer, J. Advances in Fmoc solid-phase peptide synthesis. J. Pept. Sci. Off. Publ. Eur. Pept. Soc. 2016, 22, 4-27. [CrossRef] 